\title{
Early Myocardial Remodeling after Aortic Valve Replacement
}

\author{
Deshbandhu Sharma, Sudhir Mehta ${ }^{1}$, Rajnish Pathania ${ }^{1}$ \\ Department of CTVS, Dr. RPGMC, Tanda, Himachal Pradesh, 'Department of CTVS, IGMC, Shimla, Himachal Pradesh, India \\ ORCID: \\ Deshbandhu Sharma: 0000000193067367 \\ Sudhir Mehta: 0000-0002-1028-732X \\ Rajnish Pathania: 0000-0002-2585-2846
}

\section{Abstract}

Background: Aortic valve disease leads to eccentric or concentric left ventricular (LV) hypertrophy and changes in the left ventricle function. The goal of aortic valve replacement (AVR) is to alleviate the pressure and volume overload on the left ventricle, allowing myocardial remodeling and regression of LV mass. Objectives: The objective of this study was to assess early LV remodeling in patients with severe aortic valve stenosis and/or moderate-to-severe aortic regurgitation after AVR. Materials and Methods: This prospective study was conducted in the department of cardiovascular and thoracic surgery between January 2015 and February 2016. All patients undergoing AVR exclusively over 1 year were included in the study. Patients were assessed at 1 week, 6 weeks, 3 months, and 6 months after AVR by transthoracic echocardiography. Peak and mean pressure gradients across aortic valve, LV ejection fraction, fractional shortening, LV dimensions, and LV mass along with other parameters were measured in the pre- and postoperative period. Results: A total of 33 patients with different lesions who underwent AVR were evaluated. All but one child (aged 12 years) were adults with a median age of 52 years \pm 14.6 years including 21 males and 12 females. The LV mass index (LVMI) regression occurred over time in all cases. Mean LVMI decreased to $149.20 \pm 53.7 \mathrm{~g} / \mathrm{m}^{2}$ at 1 week and $120.8 \pm 45.49 \mathrm{~g} / \mathrm{m}^{2}$ at 6 weeks of AVR from its baseline value of $180.8 \pm 58.9 \mathrm{~g} / \mathrm{m}^{2}(P<0.001)$. Six patients who were followed up to 1 year had mean LVMI $122.46 \pm 50.0 \mathrm{~g} / \mathrm{m}^{2}$. Conclusion: Marked reduction in LV mass was discerned after AVR as early as 1 week and further reduction continued up to 6 weeks; however, regression thereafter was not statistically significant.

Keywords: Aortic regurgitation, aortic stenosis, aortic valve replacement, left ventricular mass regression

\section{INTRODUCTION}

Aortic valve disease is associated with eccentric or concentric left ventricular (LV) hypertrophy and changes in the left ventricle function. ${ }^{[1]}$ It is a beneficial adaptation that compensates for high intracavitary pressure and allows wall stress and the ejection fraction to remain within the normal range. ${ }^{[2]}$ Initially, both the cardiac output and ejection fraction are maintained within normal limits. However, when wall stress exceeds the compensatory mechanism, then LV function starts declining. The overall goal of AVR is to alleviate the pressure and volume overload on the left ventricle, allowing myocardial remodeling and regression of LV mass. The time course and earliest evidence of significant LV remodeling in the form of LV mass regression, changes in end-systolic and

Received: 17-06-2021 Revised: 21-09-2021 Accepted: 23-09-2021

Published Online: 29-01-2022

\begin{tabular}{|l|l|}
\hline \multicolumn{3}{|c|}{ Access this article online } \\
\hline Quick Response Code: & Website: \\
& \\
http://www.ijcva.com
\end{tabular}

diastolic dimensions, LV ejection fraction, and transaortic gradients across aortic valve are controversial. The present study was conducted to ascertain the time course and extent of early LV remodeling in the form of LV mass, dimensions, transvalvular gradients, and function using transthoracic echocardiography (TTE) after AVR in the early postoperative period.

\section{Materials and Methods}

This prospective study was conducted in the department of cardiovascular and thoracic surgery between January 2015 and February 2016. The study was approved by the institutional

Address for correspondence: Dr. Sudhir Mehta, Department of CTVS, IGMC, Shimla, Himachal Pradesh, India. E-mail: sudheermehta09@gmail.com

This is an open access journal, and articles are distributed under the terms of the Creative Commons Attribution-NonCommercial-ShareAlike 4.0 License, which allows others to remix, tweak, and build upon the work non-commercially, as long as appropriate credit is given and the new creations are licensed under the identical terms.

For reprints contact:WKHLRPMedknow_reprints@wolterskluwer.com

How to cite this article: Sharma D, Mehta S, Pathania R. Early myocardial remodeling after aortic valve replacement. Int J Cardiovasc Acad 2021;7:119-23. 
ethics committee. All consecutive patients of all age groups undergoing aortic valve replacement (AVR) for aortic stenosis and/or aortic insufficiency over 1 year were included in the study. All patients provided signed informed consent. Patients receiving a prosthetic valve at any other location besides AVR and significant coronary artery disease were excluded. Detailed history including demographic profile, NYHA class, nature of valvular disease, and routine preoperative investigations of all cases was done and recorded. Every patient underwent TTE within a week before the operation. Type of valvular lesion, peak and mean pressure gradients, LV dimensions, fractional shortening, ejection fraction, and indexed LV mass were measured. All operations were performed under standard cardiopulmonary bypass. Native aortic valve was excised completely, and prosthetic valve was implanted at the annular position using interrupted sutures.

All patients underwent TTE after AVR at 1 week, 6 weeks, 3 months, and 6 months. Parameters such as improvement in functional class, peak and mean pressure gradients across aortic valve, LV ejection fraction, fractional shortening, LV dimensions, and LV mass were measured in the postoperative period. LV mass was calculated using an S5-1 transducer on Philips iE33 echocardiography machine according to the American Society recommendations. The examination included two-dimensional derived M-mode, continuous wave and pulse Doppler and color Doppler studies. All echocardiographic measurements were done by a single experienced cardiologist.

\section{Ethical statement}

The study protocol was approved by the Local Ethics committee. Patient Consent Declaration was obtained from the patients. The study was conducted in accordance with the Helsinki Declaration.

\section{Statistical analysis}

Postoperative measured parameters were analyzed statistically using standard statistical methods and software (SPSS Inc., Chicago, IL, USA, version 15.0 for windows). All values were expressed as mean \pm standard deviation. LV mass index (LVMI) regression, improvement in LV dimensions, and improvement in ejection fraction were assessed using paired $t$-test. $P<0.05$ was considered significant.

\section{REsULTS}

We evaluated various echocardiographic parameters preoperatively and after AVR. A total of 33 patients with different lesions who underwent AVR were recruited. Thirty patients were followed up to 6 months. Two patients were lost to follow-up after 1 week and one patient after 6 weeks. No perioperative death occurred.

All, except one (child aged 12 years), were adults. Thirty-two patients were above 18 years of age (maximum age 70 years) with median age 52 years \pm 14.6 years [Table 1].

Preoperatively, one patient was NYHA IV, 18 NYHA III, and 14 NYHA II. There was significant improvement $(P<0.05)$ in
NYHA class at 6 weeks with 5 patients NYHA III, 18 NYHA II, and 8 NYHA I. Angina was present in 10 (30.4\%) and syncope in $16(51 \%)$ cases which improved postoperatively.

\section{Left ventricular end-diastolic dimension}

$\mathrm{LV}$ end-diastolic dimension improved significantly $(P<0.001)$ from preoperative mean value of $50.24 \pm 13.17 \mathrm{~mm}$ to $42.21 \pm 12.35 \mathrm{~mm}$ at 1 week, $36.66 \pm 12.9 \mathrm{~mm}$ at 6 weeks, $38.06 \pm 7.30$ at 3 months, and $37.79 \pm 7.70$ at 6 months. Reduction continued significantly up to 6 months in respect to values at 1 week.

\section{Fractional shortening}

There was no significant change in fractional shortening (FS) after AVR till 6 weeks but a significant change in FS at 3 months with $P$ value $<0.05$ and 6 months $P<0.01$.

\section{Left ventricular ejection fraction}

Seven $(21 \%)$ patients had preoperative LV ejection fraction (LVEF) $<50 \%$, out of which 6 showed improvement. There was no improvement in LVEF in immediate postoperative period. It took 6 months for LVEF to have significant improvement $(P<0.05)$, but no significant difference was seen, when AS and mixed groups were compared to each other.

\section{Mean left ventricular mass index}

LVMI decreased to $149.20+53.7 \mathrm{~g} / \mathrm{m}^{2}$ at 1 week of AVR from its baseline value of $180.8 \pm 58.9 \mathrm{~g} / \mathrm{m}^{2}(P<0.001)$ and further reduced to $120.8 \pm 45.49 \mathrm{~g} / \mathrm{m}^{2}$ at 6 weeks. The reduction was noticed as early as 1 week $(17 \%)$ after surgery. This regression continued further at 6 weeks (30.1\%), 3 months (32.7\%), and at 6 months $(43.3 \%)$. The maximum reduction was noticed at

\begin{tabular}{lc}
\hline Table 1: Demographic data & \\
\hline Parameter & Number \\
\hline Total number of patients & 33 \\
Age (years) & \\
Mean & $50.33 \pm 14.6$ \\
Range & $12-70$ \\
Gender & \\
Males & 21 \\
Females & 12 \\
Type of lesion & \\
Aortic aortic stenosis & 19 \\
Aortic regurgitation & 4 \\
Mixed lesion (patients) & 10 \\
Types of valves used (patients) & \\
Mechanical valves & 13 \\
Bioprosthetic valves & 20 \\
Size of valves & \\
Minimum (mm) & 19 \\
Maximum (mm) & 28 \\
Mean & $21.8 \pm 2.29$ \\
Mean EOAI of the valves used & $1.36 \pm 0.76(3$ cases had patient \\
Mean cardiopulmonary bypass & $128.9 \pm 33.24$ (range 84-196) \\
time (min) & \\
\hline EOAI: Effective orifice area index &
\end{tabular}


6 weeks compared to baseline and insignificant thereafter till 6 months if compared to 6 weeks postoperatively [Figure 1]. LVMI regression occurred over time in all cases. There were 19 patients of AS, 4 of AR, and $10 \mathrm{AS} \pm \mathrm{AR}$. As AR group had just 4 patients, this group was not statistically comparable to other groups (AS and mixed). Mean LVMI preoperatively in AS group was $160.75 \mathrm{gm} / \mathrm{m}^{2}$ and $190.23 \mathrm{~g} / \mathrm{m}^{2}$ in mixed group, which reduced significantly to $79.5 \mathrm{gm} / \mathrm{m}^{2}$ in AS group $(50.5 \%)$ and $131.25 \mathrm{~g} / \mathrm{m}^{2}$ in mixed group $(31.0 \%)$ at 6 months and difference in reduction in both groups was also significant.

The comparative changes in different echocardiographic parameters are shown in Table 2 and Figure 2.

Peak systolic gradient of $76.75 \pm 26.57 \mathrm{mmHg}$ baseline (preoperative) reduced to $17.48 \pm 8.17$ at 1 week, $16.73 \pm 9.0$ at 6 weeks, $16.70 \pm 7.35$ at 3 months, and $16.10 \pm 7.34$ at 6 months postoperatively, showing a significant reduction with $P<0.001$.

Mean systolic gradient in preoperative period was $46.09 \pm 18.84 \mathrm{mmHg}$ (range $11-89 \mathrm{mmHg}$ ) which reduced to $8.60 \pm 4.6$ at 1 week, $8.06 \pm 4.84$ at 6 weeks, $8.20 \pm 3.97$ at 3 months, and $8.0 \pm 4.0$ at 6 months.

\section{Discussion}

There is a reduction in the degree of hemodynamic stress faced by the left ventricle after AVR as the stenotic or regurgitant valve

\begin{tabular}{|c|c|c|c|c|c|}
\hline Parameter & Preoperative & $\begin{array}{c}1 \\
\text { week }\end{array}$ & $\begin{array}{c}6 \\
\text { weeks }\end{array}$ & $\begin{array}{c}3 \\
\text { months }\end{array}$ & $\begin{array}{c}6 \\
\text { months }\end{array}$ \\
\hline LVED & 49.83 & 42.16 & 38.06 & 37 & 35.13 \\
\hline LVES & 31.43 & 25.83 & 24.26 & 23.36 & 22.8 \\
\hline LVEF & 62.63 & 61.1 & 63.96 & 65.9 & 68.26 \\
\hline FS & 37.83 & 37.2 & 34.06 & 38.63 & 38.83 \\
\hline LVMI & 172.68 & 138.29 & 120.81 & 116.05 & 110.9 \\
\hline MSG & 46.2 & 9 & 8.06 & 8.2 & 8 \\
\hline PSG & 75.6 & 23.7 & 16.7 & 16.7 & 16.2 \\
\hline
\end{tabular}

LVED: Left ventricular end-diastolic dimension, LVES: Left ventricular end-systolic dimension, LVEF: Left ventricular ejection fraction, FS: Fractional shortening, LVMI: Mean left ventricular mass index, MSG: Mean systolic gradient, PSG: Peak systolic gradient

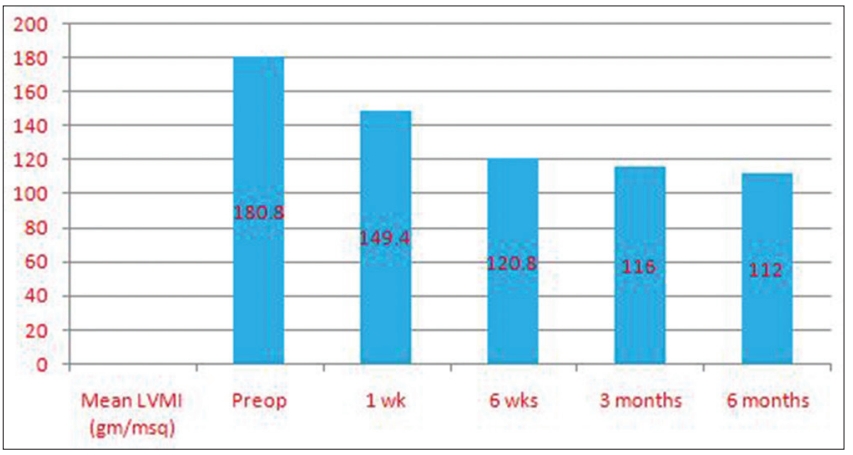

Figure 1: Regression of left ventricular mass over 6 months is replaced with a prosthetic valve. ${ }^{[3]}$ AVR reduces symptoms, increases long-term survival, and improves the quality of life in patients with aortic valve disease. ${ }^{[4]}$ The LV changes can be assessed by various methods such as echocardiography, cardiac catheterization, ultrafast computed tomography, and magnetic resonance imaging. ${ }^{[2,5]}$ Echocardiography is a noninvasive method of LV mass measurement and is the most widely used technique. It provides reproducible results of the extent of LV hypertrophy and its measurements as accurate as obtained from other invasive and expensive modalities. ${ }^{[6-9]}$ In this study, TTE was used for assessing the changes in LV functions, dimensions, and LV mass in patients with chronic aortic valve disease.

LV end-diastolic and end-systolic volumes decrease after AVR which leads to an increase in the end-systolic pressure-volume ratio, implying an improvement in contractile performance. This results in an improvement in LV function and the functional class of the patient improves with time. ${ }^{[10]}$ In this study, both LV end-diastolic and end-systolic volumes have been found to decrease significantly over 6 weeks from preoperative mean value and minimal thereafter up to 6 months. These findings are consistent with the reports in the literature which have attributed these results to an immediate decrease in LV preload and afterload following AVR. ${ }^{[10]}$

AVR decreases LV pressure and volume overload, subsequently leading to adaptation and remodeling, with regression of hypertrophy and LV mass. Ejection fraction, therefore, would be expected to improve after AVR in patients with reduced preoperative ejection fraction. Those who do not improve probably have fixed myocardial damage preoperatively due to long-standing chronic aortic valve disease. Subsequent survival has been found to be better in patients with an early improvement in ejection fraction than in patients without an improvement in ejection fraction. ${ }^{[10,11]}$ A significant improvement in postoperative LV ejection fraction of 6 out of 7 patients, who had preoperative LVEF $<50 \%$, was noted in the present study. LV mass is the most important parameter in assessing LV remodeling after AVR. The LV hypertrophy

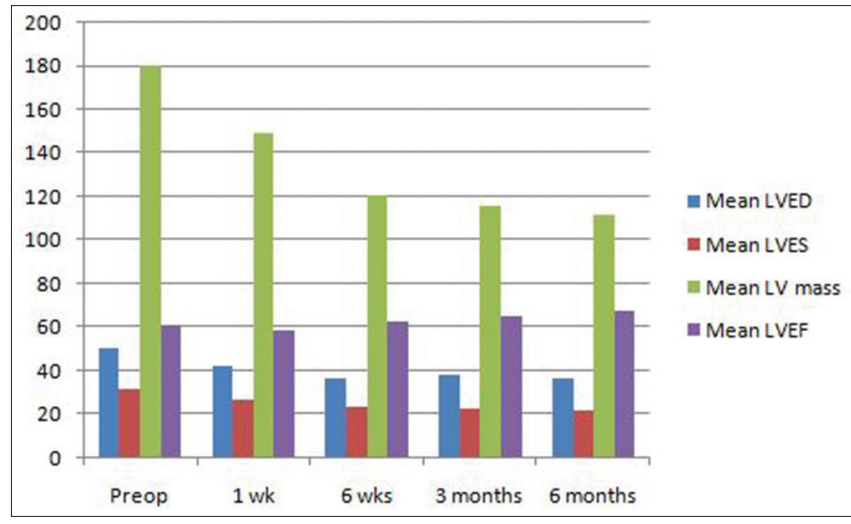

Figure 2: Comparison of improvement mean left ventricular end-diastolic dimension (LVED), left ventricular end-systolic dimension (LVES), LV mass, and left ventricular ejection fraction 
in chronic aortic valve disease is mainly due to the increase in size of myofibrils and increase in connective tissue contents. ${ }^{[12]}$ The accepted upper limit of normal LVMI derived by various modalities is $125 \mathrm{gm} / \mathrm{m}^{2}{ }^{[13,14]}$ The LV hypertrophy is an independent predictor of mortality and morbidity in patients with aortic valve disease. It is associated with a higher incidence of decreased coronary flow reserve, congestive heart failure, ventricular arrhythmias, and sudden cardiac death. ${ }^{[2]}$

LV hypertrophy regresses after AVR, but it never returns to baseline values because some amount of transvalvular gradient remains across prosthetic valves because the valve sewing ring and stents reduce the effective orifice area. ${ }^{[3,15,16]}$ Despite these prosthetic valves being somewhat stenotic, there is an immediate significant decrease in transvalvular gradient and aortic valve becomes competent, which results in a significant decrease in LV mass. ${ }^{[12]}$ In the present study, LV mass regression was noticed in all cases regardless of type and size of prosthetic valve used. Amarrelle et al. ${ }^{[17]}$ and Bech-Hanssen et al. ${ }^{[18]}$ observed a significant reduction in LVMI despite effective orifice area of a prosthetic valve being $<0.65 \mathrm{~cm}^{2} / \mathrm{m}^{2}$ and $<0.85 \mathrm{~cm}^{2} / \mathrm{m}^{2}$, respectively. However, contrary to these studies, various workers have demonstrated that increased gradient across prosthetic aortic valve results in an increased LV afterload in the patients having effective orifice area $<0.8 \mathrm{~cm}^{2} / \mathrm{m}^{2}$. This results in the persistence of LV hypertrophy and therefore, higher incidence of mortality and morbidity. ${ }^{[19-21]}$ In the present study, only three patients had effective orifice area $<0.85 \mathrm{~cm}^{2} / \mathrm{m}^{2}\left(0.81 \mathrm{~cm}^{2} / \mathrm{m}^{2}\right)$. All these showed significant LV mass reduction and improvement in LVEF despite patient prosthesis mismatch; however, this small number is insufficient to make any inference. The extent and time course of LV mass regression after AVR is still a matter of debate. Earliest documented evidence has been a $10 \%$ decrease in LV mass within $4.9 \pm 2.4$ days of surgery by Christakis et al. ${ }^{[2]}$ They further concluded that the amount of mass regression actually may have been underestimated, as there may be substantial edema in myocardial tissue in early period after AVR. Sutton et al. ${ }^{[22]}$ examined 16 patients by echocardiography and documented a $30 \%$ regression of LV mass in $42 \pm 7$ days, thus confirming that the majority of mass regression occurs early after AVR. Henry et al. ${ }^{[23]}$ demonstrated a $16 \%$ mass reduction at 6 months after AVR, with no further changes at 1 year. However, Panidis et al. ${ }^{[24]}$ using echocardiography demonstrated a nonsignificant regression at $<6$ months and a significant $34 \%$ regression at $>6$ months of AVR. In the present study, the reduction in LVMI to BSA was noticed as early as 1 week (17\%) after surgery. This regression continued further at 6 weeks $(30.1 \%), 3$ months $(32.7 \%)$, and at 6 months (43.3\%). The maximum reduction was noticed at 6 weeks and insignificant thereafter till 6 months. These findings are consistent with studies reporting early LV mass regression.

\section{Limitations}

Only four patients with isolated severe AR, so exclusive response to the particular lesion was difficult to define with this sample size and require larger study groups. No drug treatment was taken into consideration that could have affected loading conditions pre- and postoperatively.

\section{Conclusion}

Significant LV mass reduction after AVR was noticed as early as 1 week and continued up to 6 weeks; however, reduction thereafter was not significant. More LV mass regression was noticed in severe AS group as compared to mix lesion group when compared. Ejection fraction took 6 months to improve noticeably. LV dimensions and transaortic gradients improved significantly as early as 1 week after AVR.

\section{Declaration of patient consent}

The authors certify that they have obtained all appropriate patient consent forms. In the form, the patients have given their consent for their images and other clinical information to be reported in the journal. The patients understand that their names and initials will not be published and due efforts will be made to conceal their identity, but anonymity cannot be guaranteed.

\section{Financial support and sponsorship}

Nil.

\section{Conflicts of interest}

There are no conflicts of interest.

\section{RefEREnCES}

1. Ahmad N, Shahbaz A, Ghaffar A, Tufail Z, Waheed A, Khan JS. Early left ventricular remodeling after aortic valve replacement. J Ayub Med Coll Abbottabad 2007;19:6-10.

2. Christakis GT, Joyner CD, Morgan CD, Fremes SE, Buth KJ, Sever JY, et al. Left ventricular mass regression early after aortic valve replacement. Ann Thorac Surg 1996;62:1084-9.

3. Monrad ES, Hess OM, Murakami T, Nonogi H, Corin WJ, Krayenbuehl HP. Time course of regression of left ventricular hypertrophy after aortic valve replacement. Circulation 1988;77:1345-55.

4. Eichinger WB, Botzenhardt F, Günzinger R, Kemkes BM, Bleese N, Sosnowski A, et al. Left ventricular mass regression after aortic valve replacement with the mosaic bioprosthesis. J Heart Valve Dis 2002;11:529-36.

5. McGoon DC. Prosthetic reconstruction of the aortic valve. Mayo Clin Proc 1961;36:88.

6. Harken DE, Sorof HS, Taylor WJ, Lefemine AA, Gupta SK, Lunzer S. Partial and complete prosthesis in aortic insufficiency. $\mathrm{J}$ Thorac Cardiovasc Surg 1960;40:744.

7. Starr A, Edwards ML, McCord CW, Griswold HE. Aortic replacement: Clinical experience with a semi rigid ball valve prosthesis. Circulation 1963;27:779-84.

8. Barratt-Boyes BG. Homograft aortic valve replacement in aortic incompetence and stenosis. Thorax 1964;19:131-5.

9. Ross DN. Homograft replacement of the aortic valve. Lancet 1962;2:487-90.

10. Morris JJ, Schaff HV, Mullany CJ, Rastogi A, McGregor CG, Daly RC, et al. Determinants of survival and recovery of left ventricular function after aortic valve replacement. Ann Thorac Surg 1993;56:22-30.

11. Connolly HM, Oh JK, Orszulak TA, Osborn SL, Roger VL, Hodge DO, et al. Aortic valve replacement for aortic stenosis with severe left ventricular dysfunction. Prognostic indicators. Circulation 1997;95:2395-400.

12. Del Rizzo DF, Goldman BS, Christakis GT, David TE. Hemodynamic benefits of the toronto stentless valve. J Thorac Cardiovasc Surg 1996;112:1431-45.

13. Devereux RB, Alonso DR, Lutas EM, Gottlieb GJ, Campo E, Sachs I, 
et al. Echocardiographic assessment of left ventricular hypertrophy: Comparison to necropsy findings. Am J Cardiol 1986;57:450-8.

14. Kennedy JW, Baxley WA, Figley MM, Dodge HT, Blackmon JR. Quantitative angiocardiography. I. The normal left ventricle in man. Circulation 1966;34:272-8.

15. Tasca G, Brunelli F, Cirillo M, Amaducci A, Mhagna Z, Troise G, et al. Mass regression in aortic stenosis after valve replacement with small size pericardial bioprosthesis. Ann Thorac Surg 2003;76:1107-13.

16. Garner C, Lecomte E, Visvikis S, Abergel E, Lathrop M, Soubrier F. Genetic and environmental influences on left ventricular mass. A family study. Hypertension 2000;36:740-6.

17. Amarelli C, Della Corte A, Romano G, Iasevoli G, Dialetto G, De Santo LS, et al. Left ventricular mass regression after aortic valve replacement with $17-\mathrm{mm}$ St Jude medical mechanical prostheses in isolated aortic stenosis. J Thorac Cardiovasc Surg 2005;129:512-7.

18. Bech-Hanssen O, Caidahl K, Wall B, Mykén P, Larsson S, Wallentin I. Influence of aortic valve replacement, prosthesis type, and size on functional outcome and ventricular mass in patients with aortic stenosis. J Thorac Cardiovasc Surg 1999;118:57-65.

19. Del Rizzo DF, Abdoh A, Cartier P, Doty D, Westaby S. Factors affecting left ventricular mass regression after aortic valve replacement with stentless valves. Semin Thorac Cardiovasc Surg 1999;11:114-20.

20. Blais C, Dumesnil JG, Baillot R, Simard S, Doyle D, Pibarot P. Impact of valve prosthesis-patient mismatch on short-term mortality after aortic valve replacement. Circulation 2003;108:983-8.

21. Pibarot P, Dumesnil JG. Haemodynamic and clinical impact of prosthesis-patient mismatch in aortic valve position and its prevention. J Am Coll Cardiol 2000;36:1131-41.

22. Sutton M, Plappert T, Spiegel A, Raichlen J, Douglas P, Reichek N, et al. Early postoperative changes in left ventricular chamber size, architecture and function in aortic stenosis and aortic regurgitation and their relation to intraoperative changes in after load. A prospective two dimensional echocardiographic study. Circulation 1987;76:77-89.

23. Henry WL, Bonow RO, Borer JS, Kent KM, Ware JH, Redwood DR, et al. Evaluation of aortic valve replacement in patients with valvular aortic stenosis. Circulation 1980;61:814-25.

24. Panidis IP, Kotler MN, Ren JF, Mintz GS, Ross J, Kalman P. Development and regression of left ventricular hypertrophy. J Am Coll Cardiol 1984;3:1309-20. 